Dr. Beveridge gave evidence contrary to the belief that phospholipids comprise a vehicle for the transportation of fatty acids, although he pointed out that the phospholipids as $\beta$-lipoproteins may play a part in the transport of neutral fat. Finally, he quoted from the literature in support of the theory that choline-containing phospholipids facilitate the oxidation of fatty acids. He emphasized that no single function of the phospholipids could be stated in a positive manner. Dr. O. F. Denstedt (McGill University) commented on the physico-chemical function of phospholipids at biological interfaces.

JAMES F. BERRY

\section{MELTING OF SOLIDS SYMPOSIUM IN OTTAWA}

A SYMPOSIUM on melting, diffusion and related topics was held during October 24-25 at the National Research Council Laboratories, Sussex Drive, Ottawa, under the chairmanship of Dr. D. K. C. MacDonald. The meeting was held at the invitation of the Low Temperature and Solid State Physics Group of the Division of Pure Physics, National Research Council of Canada, for the purpose of bringing together scientists within easy reach of Ottawa interested in melting from the different points of view of chemist, geophysicist, metallurgist and physicist. Twelve lectures were given; fifty minutes was allotted to each, of which about twenty was reserved for questions and discussion. It was found that this schedule allowed each speaker time for an adequate exposition of his subject, while preserving the balance of lecture and discussion.

A contrast soon became apparent between the working concepts of the physicists and chemists and those of the metallurgists. The physicists and chemists tended to regard both solid and liquid as homogeneous down to atomic dimensions, and thought in terms of thermodynamies and statistical mechanics. Thus, in his introductory lecture, Dr. MacDonald discussed self-diffusion and melting, using the model of 'hole' formation in the crystal lattice, and outlined the evidence which suggests that melting occurs when the hole concentration has risen to the order of $10^{-3}$. J. S. Dugdale (National Research Council) gave a comprehensive review of both experimental and theoretical work on the behaviour of the melting curve at high pressures. Two papers from Chalk River described investigations of structure and diffusion in liquids using slowneutron diffraction: D. G. Henshaw and D. G. Hurst have determined radial distribution functions in liquid helium, which show marked increase in short. range order with increase of pressure; and B. N. Brockhouse has made some preliminary messurements of the energy distribution in neutrons scattered from liquids, data which, after suitable analysis, can give information about self-diffusion and timedependent pair distribution functions in the liquid. J. A. Morrison (National Research Council) described experiments on surface melting in adsorbed layers of argon and nitrogen on substrates of titanium oxide, with an anomaly in specific heat becoming rapidly sharper as the thickness of the layer increased. The interpretation of these results was discussed by D. C. Patterson (University of Montreal), using an orderdisorder model for melting, and later by the meeting at large.
W. B. Pearson (National Research Council) described experiments on dilute alloys illustrating the effects of lattice distortion upon melting temperatures. The other metallurgists were concerned to make plain the inhomogeneous nature of the melting process, making use of photographs of the melting and freezing interfaces in metals. A. Rosenberg (University of Toronto) showed that freezing in 'pure' lead takes place by lamellar growth, and that melting appears to be the same process in reverse; this was effectively illustrated in a film using suitable space and time magnification. J. W. Rutter (University of Toronto) described the freezing of impure metals and showed how the formation of impurity substructures depends upon the concentration of impurity, rate of freezing, and temperature gradient in the liquid. E. H. McLaren (National Research Council) has used precision $\left(10^{-4} \mathrm{deg}\right.$. C.) resistance thermometry for investigating the freezing and melting temperatures of zine and tin, and has found that differences of freezing technique and thermal history can cause changes up to about $10^{-2}$ deg. C. In a brief, provocative talk, W. C. Winegard (University of Toronto) emphasized the difference of outlook of physicist and metallurgist and criticized the theories of the former for taking no account of the impurities and dislocations which are known to play an important part in melting. A lively discussion followed, profitable because the participants had already listened to uninterrupted expositions of each other's work.

Any doubts of the usefulness of even the crudest of fundamental theories was dispelled by R. J. Uffen (University of Western Ontario), who described how knowledge of the physics of condensed phases is used in attempts to deduce the composition and state of the Earth's mantle and core. For this purpose not nearly enough is yet known about the physics of high pressures, and bold extrapolations from laboratory pressures have to be made. The success of the symposium makes it probable that similar meetings will be arranged for the discussion of other subjects related to work in low-temperature and solid-state physics.

T. H. K. BARRON

\section{CHEMICAL COMPOSITION OF PARTHIAN COINS}

$\mathrm{A}$

$\mathrm{N}$ outstanding example of the value of accurate and complete chemical analyses in the investigation of ancient metals, when these are afterwards interpreted by an ingenious mind, is given in a monograph on the "Chemical Composition of Parthian Coins", by Earle R. Caley, published by the American Numismatic Society, New York (Numismatic Notes and Monographs, No. $129 ; 1955)$. The author has made a large number of analyses of Parthian silver and bronze coins not only for the major constituents but also for minor impurities. There is internal evidence that these are reliable, and much new light is thrown on a field of historical metallurgy concerning which knowledge has hitherto been most meagre.

An elegant piece of detective research has revealed, practically beyond doubt, the materials from which the debased silver coins of the King Orodes I (5738/37 B.c.) were made. From analyses of silver coins of the highest fineness for the time, it is shown that 